\title{
Differential quadrature method for free vibration analysis of coupled shear walls
}

\author{
K.B. Bozdogan* \\ Department of Civil Engineering, Cumhuriyet University, Sivas, Turkey \\ (Received January 6, 2011, Revised July 17, 2011, Accepted November 30, 2011)
}

\begin{abstract}
Differential Quadrature Method (DQM) is a powerful method which can be used to solve numerical problems in the analysis of structural and dynamical systems. In this study the governing equation which represents the free vibration of coupled shear walls is solved using the DQM method. A one-dimensional model has been used in this study. At the end of study various examples are presented to verify the accuracy of the method.
\end{abstract}

Keywords: differential quadrature method; coupled shear wall; free vibration; continuum model; sandwich beam

\section{Introduction}

Shear walls are structural systems commonly used in the construction of high rise buildings to increase resistance to horizontal loads, such as wind and seismic loads acting on the buildings. They are specifically designed to react to these kinds of loads, by taking into consideration the environmental features and stipulated building codes of the country. Shear walls which have openings and vertical rows for windows and doors, due to architectural concerns, are called coupled shear walls.

There are a great number of studies dealing with the vibrational analysis of high-rise buildings containing coupled shear walls in their structure (Rosman 1964, Smith 1970, Cheung et al. 1977, Basu et al. 1979, Coull and Smith 1984, Chaallal 1992, Kwan 1993, 1995, Li and Choo 1996, Chaallal and Ghmallar 1996, Chaallal et al. 1996, Kuang and Chau 1998, Ha and Tan 1999, Rashed 2000, Kim and Lee 2003, Aksogan et al. 2003, Zeidabadi et al. 2004, Wang and Wang 2005, Aksogan et al. 2007, Bozdogan et al. 2009, Resatoglu et al. 2010, Takabatake 2010).

Rosman (1964) proposed a continuous medium method for a pair of high rise coupled shear walls. Basu (1979) presented the seismic design charts for buildings containing coupled shear walls. In the study of Li and Choo (1996) a hybrid approach that is based on the analysis of equivalent continuous medium and a discrete lumped mass system for free vibration analysis of stiffened pierced walls on flexible foundations was proposed.

On the other hand several modeling approaches and numerical solutions are suggested in these

*Corresponding author, Ph.D, E-mail: kbbozdogan@yahoo.com.tr 
studies and in the literature for free vibration analysis of the buildings that contain coupled shear walls in their structures. Most of them make use of numerical differentiation in calculations. Although computational power and the speed of computer technology is increasing rapidly, numerical methods and algorithms should meet the increasing amount of data. The finite difference method is a wellknown numerical method used to approximate the derivatives of differential equations. However convergence to the solution is slow.

In this study, we propose a method that employs Differential Quadrature Method (DQM) for free vibration analysis of structures containing coupled shear walls based on the continuous system model.

Similar studies in the past used conventional numerical methods, such as the Finite Difference (FE) Method to approximate the derivatives of the differential equation that describes the dynamical behavior of the structures with coupled shear walls. The proposed method improves upon past studies by utilizing DQM, which is designed for free vibration of the buildings having coupled shear walls under horizontal loads thereby converging to the solution faster than the methods presented in literature. In addition, DQM solutions are the most accurate among the solutions proposed so far.

\section{Differential quadrature method}

DQM rapidly converges to a fairly accurate numerical solution of differential equations in engineering problems. There are numerous (numerical) approximation of derivatives in numerical analysis; however, most of them lack simplicity and efficiency in algorithmic construction and computation aspects. Unlike conventional methods such as Finite Differences (FD) and FE, DQM requires less grid points to obtain acceptable accuracy. Proposed by Bellman et al. (1971, 1972), DQM is an accurate method for solution of nonlinear differential equations in approximation of the derivatives.

The successful application of DQM in mechanics has been demonstrated numerous researchers (Bert et al. 1987, Striz et al. 1988, Shu and Richards 1992, Bert et al. 1993, Striz et al. 1995, Bert and Malik 1996a, Bert and Malik 1996b, Shu and Hue 1997, Liew et al. 1999, Liew and Teo 1999, Liew et al. 2001, Karami and Malekzadeh 2003, Civalek 2004a, Civalek and Ülker 2004, Civalek 2005, Malekzadeh and Farid 2007, Kaya 2010, Efthekhari and Jafari 2011).

Another advantages of DQM is that it transforms the differential equations into a set of analogous algebric equations in terms of the unknown function values at the resampled points in the solution domain (Civalek 2004b).

\section{System model}

Coupled shear walls do not exhibit Timoshenko or Euler Bernoulli beam behavior. Rather, they behave as a beam having a combination of the two. A beam exhibits both is defined as sandwich beam (Fig. 1).

\section{Governing equations and boundary conditions}

The governing equations of coupled shear walls can be written as 


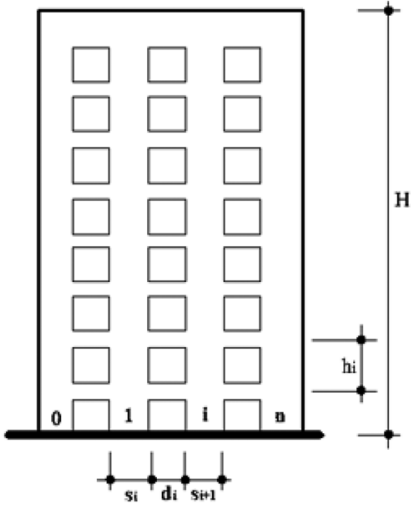

(a) Coupled shear wall

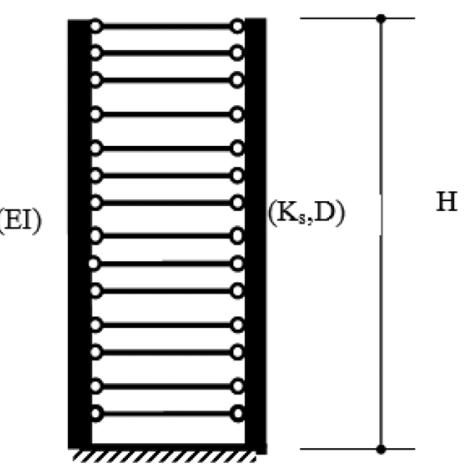

(b) Sandwich beam model

Fig 1. Physical model of coupled shear wall

$$
E I \frac{\partial^{4} U(z, t)}{\partial z^{4}}-K_{s} \frac{\partial^{2} U(z, t)}{\partial z^{2}}+K_{s} \frac{\partial^{2} U_{b}(z, t)}{\partial z^{2}}+p \frac{\partial^{2} U(z, t)}{\partial t^{2}}=0
$$

where $p$ is the mass per unit length, $U$ represents the total shape function, $z$ represents the vertical axis, $d U_{b} / d z$ represents the rotation angle of bending of coupled shear walls

$U$ and $U_{b}$ are to be a function of circular frequency $\omega$

$$
\begin{aligned}
U(z, t) & =X(z) \sin (\omega t) \\
U_{b}(z, t) & =X_{b}(z) \sin (\omega t)
\end{aligned}
$$

When the Eq. (2) is substituted into Eq. (1), the resulting Eq. (3) is

$$
E I \frac{d^{4} X}{d z^{4}}-K_{s} \frac{d^{2} X}{\partial z^{2}}+K_{s} \frac{d^{2} X}{d z^{2}}-p \omega^{2} X=0
$$

The shear force equilibrium for beam on the right side (Fig. 1) can be written as

$$
D \frac{d^{3} X_{b}}{d z^{3}}+K_{s} \frac{d X}{d z}-K_{s} \frac{d X_{b}}{d z}=0
$$

$K_{s}$ is the equivalent shear rigidity of coupled shear walls (Fig. 2) and can be calculated as (Potzta and Kollar 2003)

$$
K_{s}=\frac{1}{\left(\frac{1}{R_{w}}+\frac{1}{R_{b}}\right)}
$$

where $R_{w}$ is

$$
R_{w}=\sum_{j=0}^{n} \frac{12 E I_{p j}}{h_{i}^{2}}
$$




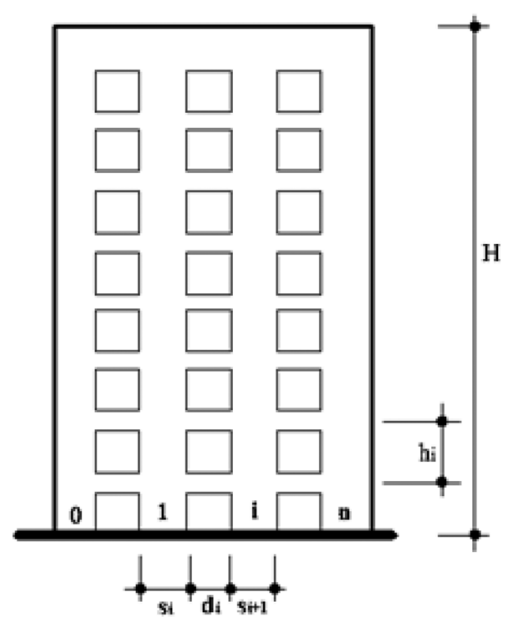

Fig. 2 Coupled shear wall

For coupled shear walls which consists of $n$ walls and $n-1$ connecting beams, $R_{b}$ can be calculated from Eq. (7) (Potzta and Kollar 2003)

$$
R_{b}=\sum_{j=1}^{n-1} \frac{6 E I_{b j}\left[\left(d_{j}+s_{j}\right)^{2}+\left(d_{j}+s_{j+1}\right)^{2}\right]}{d_{j}^{3} h\left(1+\frac{12 k E I_{b j}}{G A_{b j} d_{j}^{2}}\right)}
$$

where, $h$ is the height of the storey, $d_{j}$ and $s_{j}$ are the length of the $j^{\text {th }}$ wall (Fig. 2).

$E I_{b j}$ and $G A_{b j}$ represent the flexural rigidity of the connecting beam and the shear rigidity of connecting them, respectively. $k$ is the constant that depends on the shape of the cross-section of the beams ( $k=1.2$ for rectangular cross-sections).

$E I$ is the total bending rigidity of the shear walls and $D$ represents the global bending rigidity of the coupled shear wall that can be calculated as

$$
D=\sum_{j=1}^{n} E A_{j} r_{j}^{2}
$$

where $A_{j}$ is the cross sectional area of the $j^{\text {th }}$ shear wall, $n$ is the number for walls and $r_{j}$ is the distance of the $j^{\text {th }}$ shear wall from the center of the cross sections.

The non-dimensional form of the governing Eqs. (3) and (4) can be written as

$$
\begin{gathered}
\frac{d^{4} X}{d \xi^{4}}-k^{2} \frac{d^{2} X}{d \xi^{2}}+k^{2} \frac{d^{2} X_{b}}{d \xi^{2}}-m X=0 \\
\frac{d^{3} X_{b}}{d \xi^{3}}+s^{2} \frac{d X}{d \xi}-s^{2} \frac{d X_{b}}{d \xi}=0
\end{gathered}
$$

The parameters $\xi, k, s$ and $m$ are defined in Table 1 . 
Table 1 The Parameters used in the problem and their definitions

\begin{tabular}{cc}
\hline \hline Parameter & Definition \\
\hline$\xi$ & $\frac{z}{H}$ \\
$s$ & $H \sqrt{\frac{K_{s}}{E I}}$ \\
$m$ & $H \sqrt{\frac{K_{s}}{D}}$ \\
\hline
\end{tabular}

The boundary conditions of a coupled shear wall can be written as

$$
\begin{gathered}
X(0)=0 \\
\frac{d X(0)}{d \xi}=0 \\
\frac{d X_{b}(0)}{d \xi}=0 \\
\frac{d^{2} X(1)}{d \xi^{2}}=0 \\
\frac{d^{2} X_{b}(1)}{d \xi^{2}}=0 \\
\frac{d^{3} X(1)}{d \xi^{3}}-k^{2}\left(\frac{d X(1)}{d \xi}-\frac{d X_{b}(1)}{d \xi}\right)=0
\end{gathered}
$$

\section{Solution of the governing equations for wall-frame structures using DQM}

We consider a one- dimensional problem, as shown in Fig. 3. It is assumed that the function $X(\xi)$ is smooth over the whole domain.

If it is assumed that $X$ and $X_{b}$ are polynomials of degree $n-1$, the function of $X$ can be written as (Shu 2000)

$$
X=\sum_{i=1}^{n} a_{i-1} * \xi^{i-1}
$$




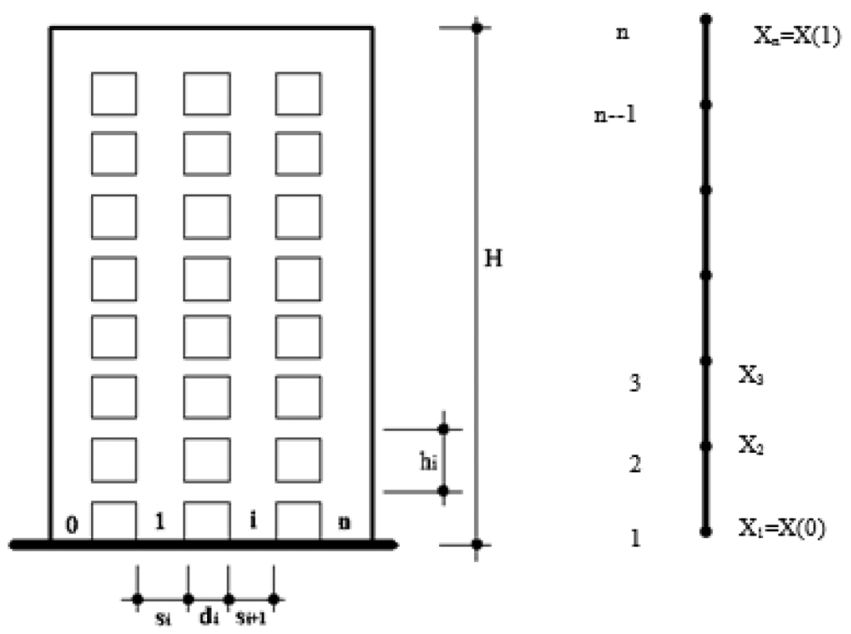

Fig. 3. Discretization of one dimensional problem

$$
X_{b}=\sum_{i=1}^{n} b_{i-1} * \xi^{i-1}
$$

where $a_{i-1}$ is the coefficient vector and $n$ is the number of nodes.

Using Eq. (17) and Eq. (18), the derivatives of $X$ and $X_{b}$ of $\xi$ can be written as

$$
\begin{gathered}
\frac{d X}{d \xi}=\sum_{i=1}^{n}(i-1) * a_{i-1} * \xi^{i-2} \\
\frac{d X_{b}}{d \xi}=\sum_{i=1}^{n}(i-1) * b_{i-1} * \xi^{i-2} \\
\frac{d^{2} X}{d \xi^{2}}=\sum_{i=1}^{n}(i-1) *(i-2) * a_{i-1} * \xi^{i-3} \\
\frac{d^{2} X_{b}}{d \xi^{2}}=\sum_{i=1}^{n}(i-1) *(i-2) * b_{i-1} * \xi^{i-3} \\
\frac{d^{3} X}{d \xi^{3}}=\sum_{i=1}^{n}(i-1) *(i-2) *(i-3) * a_{i-1} * \xi^{i-4} \\
\frac{d^{3} X_{b}}{d \xi^{3}}=\sum_{i=1}^{n}(i-1) *(i-2) *(i-3) * b_{i-1} * \xi^{i-4} \\
\frac{d^{4} X}{d \xi^{4}}=\sum_{i=1}^{n}(i-1) *(i-2) *(i-3) *(i-4) * a_{i-1} * \xi^{i-5}
\end{gathered}
$$




$$
\frac{d^{4} X_{b}}{d \xi^{4}}=\sum_{i=1}^{n}(i-1) *(i-2) *(i-3) *(i-4) * b_{i-1} * \xi^{i-5}
$$

Then the functional values in the whole domain are

$$
\begin{gathered}
X_{1}=X(0)=a_{0} \\
X_{b 1}=X_{b}(0)=b_{0} \\
X_{2}=X(h)=a_{0}+a_{1} h+\ldots \ldots+a_{1} h^{n} \\
X_{b 2}=X_{b}(h)=b_{0}+b_{1} h+\ldots \ldots+b_{1} h^{n} \\
X_{n}=X\left(n^{*} h-h\right)=a_{0}+a_{1} *\left(h^{*} n-h\right)+\ldots \ldots+a_{n} *\left(h^{*} n-h\right)^{n} \\
X_{b n}=X_{b}\left(n^{*} h-h\right)=b_{0}+b_{1} *\left(h^{*} n-h\right)+\ldots . .+b_{n} *\left(h^{*} n-h\right)^{n}
\end{gathered}
$$

Where $h$ is the distance of two grid points and is equal to $1 /(n-1)$.

Eq. (29) represents the matrix form of Eqs. (27.1), (27.2).... (27.n)

$$
\left[\begin{array}{c}
X_{1} \\
X_{2} \\
\cdot \\
\cdot \\
\cdot \\
X_{n-1} \\
X_{n}
\end{array}\right]=\left[\begin{array}{cccccc}
1 & 0 & \cdot & \cdot & 0 \\
1 & h & \cdot & \cdot & h^{n} \\
\cdot & \cdot & \cdot & \cdot & \cdot \\
\cdot & \cdot & \cdot & \cdot & \cdot \\
\cdot & \cdot & \cdot & \cdot & \cdot \\
1(n-2) * h & \cdot & \cdot & \cdot \\
1(n-1)^{*} h & . & . & \cdot & (n-2)^{n} * h^{n} \\
\cdot \\
\cdot \\
a_{n-1} \\
a_{n}
\end{array}\right]=A\left[\begin{array}{c}
a_{0} \\
a_{1} \\
\cdot \\
\cdot \\
\cdot \\
a_{n-1} \\
a_{n}
\end{array}\right]
$$

Eq. (30) shows the matrix form of Eqs. (28.1), (28.2).... (28.n)

$$
\left[\begin{array}{c}
X_{b 1} \\
X_{b 2} \\
\cdot \\
\cdot \\
\cdot \\
X_{b(n-1)} \\
X_{b n}
\end{array}\right]=\left[\begin{array}{cccccc}
1 & 0 & . & . & 0 \\
1 & h & \cdot & \cdot & h^{n} \\
\cdot & \cdot & \cdot & \cdot & \cdot \\
\cdot & \cdot & \cdot & \cdot & \cdot \\
\cdot & \cdot & \cdot & \cdot & \cdot \\
1(n-2) * h & . & \cdot & \cdot \\
1(n-1) * h-2)^{n} * h^{n}
\end{array}\right]\left[\begin{array}{c}
b_{0} \\
b_{1} \\
\cdot \\
\cdot \\
\cdot \\
b_{n-1} \\
b_{n}
\end{array}\right]=B\left[\begin{array}{c}
b_{0} \\
b_{1} \\
\cdot \\
\cdot \\
\cdot \\
b_{n-1} \\
b_{n}
\end{array}\right]
$$

Using Eqs. (19), (20) and (23), Eq. (10) can be written as

$$
\sum_{i=1}^{n}(i-1) *(i-2) *(i-3) * b_{i-1} * \xi^{i-4}+s^{2} \sum_{i=1}^{n}(i-1) * a_{i-1} * \xi^{i-2}-s^{2} \sum_{i=1}^{n}(i-1) * b_{i-1} * \xi^{i-2}=0
$$

Using Eq. (31), Matrix Eq. (32) can be written as 


$$
C\left[\begin{array}{c}
a_{0} \\
a_{1} \\
\cdot \\
\cdot \\
\cdot \\
a_{n-1} \\
a_{n}
\end{array}\right]=D\left[\begin{array}{c}
b_{0} \\
b_{1} \\
\cdot \\
\cdot \\
\cdot \\
b_{n-1} \\
b_{n}
\end{array}\right]
$$

The elements of matrices $C$ and $D$ can be written as

$$
\begin{aligned}
& C(1,1)=1 \\
& C(i, i)=s^{2 *}(i-1) \quad i=2 \ldots \ldots n \\
& C(i, j)=C(j, i)=0 \quad i \neq j \\
& D(1,1)=1 \\
& D(i, i)=s^{2 *}(i-1) \quad i=2 \ldots \ldots n \\
& D(i, i+2)=-(i+1) *(i) *(i-1) \quad i=2 \ldots \ldots n \\
& D(i, j)=0 \quad i \neq j \quad \text { and } \quad j \neq i+2
\end{aligned}
$$

Using Eqs. (25), (21), (22), (17) in Eqs. (9) and Eq. (11), (12), (13), (14), (15), (16); Matrix Eq. (40) is formed as given in the equation

$$
E\left[\begin{array}{c}
a_{0} \\
a_{1} \\
\cdot \\
\cdot \\
\cdot \\
a_{n-1} \\
a_{n}
\end{array}\right]=F\left[\begin{array}{c}
b_{0} \\
b_{1} \\
\cdot \\
\cdot \\
\cdot \\
b_{n-1} \\
b_{n}
\end{array}\right]
$$

The components of the matrices $E$ and $F$ are to be as follow.

$$
\begin{gathered}
E(1,1)=1 \\
E(1, i)=0 \quad i=2 \ldots \ldots . n \\
F(1, i)=0 \quad i=1 \ldots \ldots . n \\
E(2,2)=1 \\
E(2, i)=0 \quad i=1,3 ., 4 \ldots . . n
\end{gathered}
$$




$$
\begin{gathered}
F(2, i)=0 \quad i=1 \ldots \ldots . n \\
F(3,2)=1 \\
F(3, i)=0 \quad i=1,3 ., 4 \ldots \ldots . n \\
E(3, i)=0 \quad i=1 \ldots \ldots . n \\
E(n-2, i)=(i-1) *(i-2) \quad i=1 \ldots \ldots . n \\
F(n-2, i)=0 \quad i=1 \ldots \ldots . . \\
F(n-1, i)=(i-1) *(i-2) \quad i=1 \ldots \ldots n \\
E(n-1, i)=0 \quad i=1 \ldots \ldots . . \\
E(n, i)=(i-1) *(i-2) *(i-3)-k^{2 *}(i-1) \quad i=1 \ldots . . n \\
E(n, i)=-k^{2 *}(i-1) \quad i=1 \ldots \ldots . n
\end{gathered}
$$

$E(j, i)=(i-1) *(i-2) *(i-3) *(i-4) *(j * h-h)^{i-5}-k^{2 *}(i-1) *(i-2) *(j * h-h)^{i-3}-m^{*}\left(j^{*} h-h\right)^{i-1}$

$$
F(j, i)=-k^{2 *}(i-1) *(i-2) *\left(j^{*} h-h\right)^{i-3}
$$

Using Eq. (32), Eq. (58) can be written as

$$
\left[\begin{array}{c}
b_{0} \\
b_{1} \\
\cdot \\
\cdot \\
\cdot \\
b_{n-1} \\
b_{n}
\end{array}\right]=D^{-1} C\left[\begin{array}{c}
a_{0} \\
a_{1} \\
\cdot \\
\cdot \\
\cdot \\
a_{n-1} \\
a_{n}
\end{array}\right]
$$

By using Eq. (58) in Eq. (40)

$$
E\left[\begin{array}{c}
a_{0} \\
a_{1} \\
\cdot \\
\cdot \\
\cdot \\
a_{n-1} \\
a_{n}
\end{array}\right]=F D^{-1} C\left[\begin{array}{c}
a_{0} \\
a_{1} \\
\cdot \\
\cdot \\
\cdot \\
a_{n-1} \\
a_{n}
\end{array}\right]=\left(E-F D^{-1} C\right)\left[\begin{array}{c}
a_{0} \\
a_{1} \\
\cdot \\
\cdot \\
\cdot \\
a_{n-1} \\
a_{n}
\end{array}\right]=\left[\begin{array}{c}
0 \\
0 \\
\cdot \\
\cdot \\
\cdot \\
0 \\
0
\end{array}\right]
$$

are obtained.

Finally, using Eq. (29) and Eq. (59), Eq. (60) can be obtained 


$$
\left(E-F D^{-1} C\right) A^{-1}\left[\begin{array}{c}
X_{1} \\
X_{2} \\
\cdot \\
\cdot \\
\cdot \\
X_{n-1} \\
X_{n}
\end{array}\right]=Z\left[\begin{array}{c}
X_{1} \\
X_{2} \\
\cdot \\
\cdot \\
\cdot \\
X_{n-1} \\
X_{n}
\end{array}\right]=\left[\begin{array}{c}
0 \\
0 \\
\cdot \\
\cdot \\
\cdot \\
0 \\
0
\end{array}\right]
$$

The values of $\omega$ which set the determinant of $Z$ matrix to zero, which include the weight coefficients, are the circular frequencies.

\section{Numerical examples}

In order to verify the presented method, three numerical examples have been solved by a program written in MATLAB. The results are compared with those found in literature.

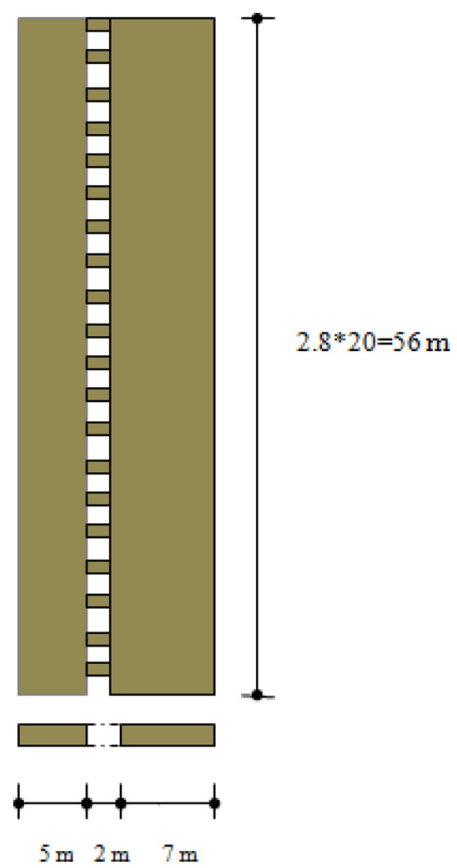

Fig. 4. A 20 storey coupled shear wall 
Table 2 The numerical data for the coupled shear wall (Example 1)

\begin{tabular}{cc}
\hline \hline Geometric and Structural Properties of Coupled Shear Wall \\
\hline Young Modulus & $3.6^{*} 10^{10} \mathrm{~N} / \mathrm{m}^{2}$ \\
Mass Density & $2.4^{*} 10^{3} \mathrm{~kg} / \mathrm{m}^{3}$ \\
Poisson Ratio & 0.15 \\
Total storeys & 20 \\
Total Height & 56 \\
Thickness of Left Side Wall & 0.3 \\
Width of Left Side Wall & 5.0 \\
Thickness of Right Side Wall & 0.3 \\
Width of Right Side Wall & 7.0 \\
Thickness of Lintel & 0.3 \\
Height of Lintel & 0.4 \\
Length of Lintel & 2.0 \\
\hline
\end{tabular}

Table 3 Natural frequencies for Example $1(\mathrm{rd} / \mathrm{s})$

\begin{tabular}{cccc}
\hline \hline Mode & $\begin{array}{c}\text { NASTRAN } \\
\text { Takabatake }(2010)\end{array}$ & DQM (n=13) & DQM $(\mathrm{n}=15)$ \\
\hline 1 & 13.09 & 12.94 & 12.94 \\
2 & 55.55 & 57.63 & 57.57 \\
3 & 129.00 & 149.63 & 140.86 \\
4 & 224.90 & - & 254.72 \\
\hline
\end{tabular}

\section{Example 1}

A 20-storey building with coupled shear wall system (Fig. 4) is analyzed in this example. The numerical data for the coupled shear wall are given in Table 2. The first four natural frequencies are calculated by using DQM and compared with those found in the literature (Takabatake 2010) in Table 3. In the study of Takabatake (2010) NASTRAN is used to solve the problem.

\section{Example 2}

Consider the coupled shear wall system shown in Fig. 5. The coupled shear wall with three bays consists of 12 storeys, has the following properties: $E=20 * 10^{10} \mathrm{kN} / \mathrm{m}^{2}, p=24 \mathrm{kN} / \mathrm{m}^{3}$.

The height of each connecting beams is $31 \mathrm{~cm}$ and the thickness of the wall is $16 \mathrm{~cm}$ everywhere. The coupled shear wall is taken from the study of (Aksogan et al. 2007) and the problem in the study is analyzed in both aspects using continuous connection and finite element methods. Free vibration analysis is carried out and it is compared to those found in the literature (Aksogan et al. 2007) (Table 4). 


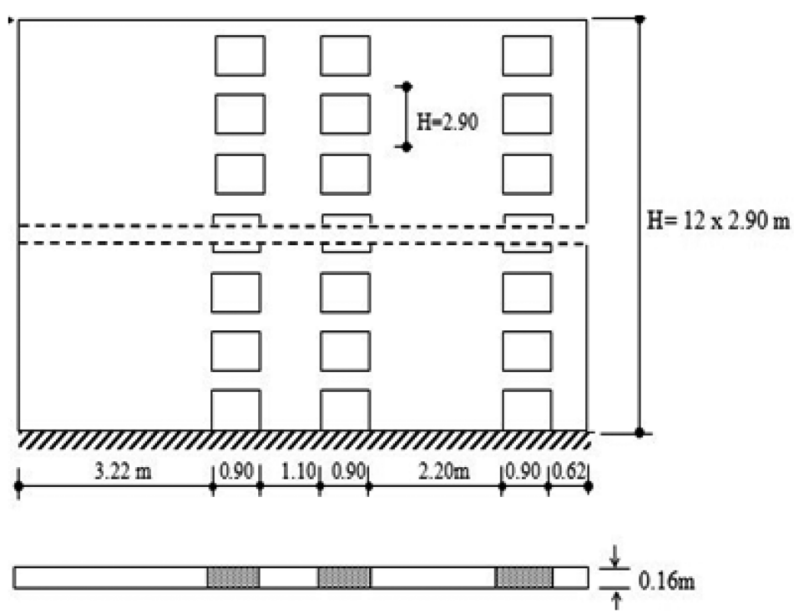

Fig. 5 Geometric properties of structure in Example 2

Table 4 Comparison of natural frequencies in Example $2(\mathrm{~Hz})$

\begin{tabular}{cccc}
\hline \hline Mode & SAP 2000 & DQM (n=13) & DQM $(\mathrm{n}=15)$ \\
\hline 1 & Aksogan et al. $(2007)$ & 3.042 & 3.070 \\
2 & 3.030 & 12.512 & 12.288 \\
3 & 12.004 & 27.462 & 26.536 \\
4 & 25.969 & - & 42.739 \\
\hline
\end{tabular}

Example 3

A twenty-six storey building, with coupled shear walls, is designed by taking into consideration the seismic loads of the zone it is built in (Fig. 6).

The horizontal loads are counteracted by six parallel coupled shear walls whose properties are given as follows:

The thickness of the shear wall is $0.305 \mathrm{~m}$ and the thickness of the floor slab is $0.203 \mathrm{~m}$. Also $d_{1}=1.68 \mathrm{~m}, s_{1}=s_{2}=7.32 \mathrm{~m}, H=71.32 \mathrm{~m}, h=2.743 \mathrm{~m}, E=25^{*} 10^{6} \mathrm{kN} / \mathrm{m}^{2}$. The distributed mass of the building (per unit height) is estimated to be $327.3 * 10^{3} \mathrm{~kg} / \mathrm{m}$.

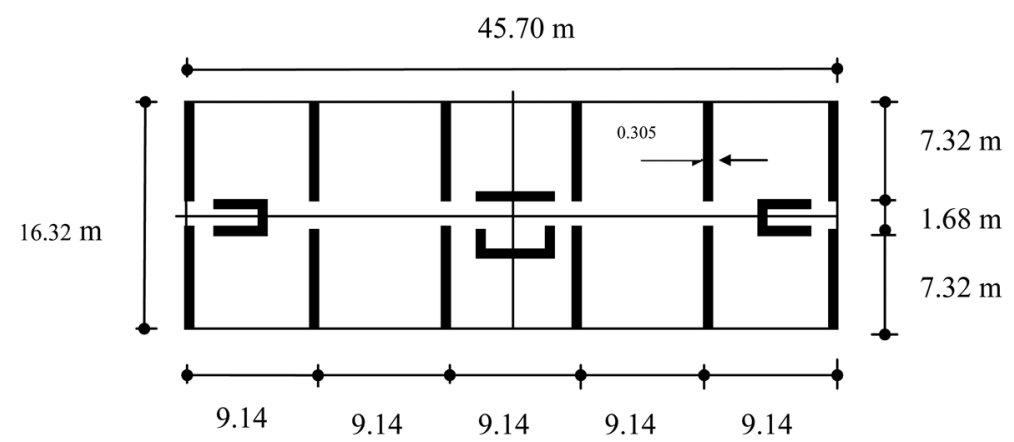

Fig. 6 Floor plan of 26- story flat- slab shear wall building (Example 3) 
Table 5 Comparison of natural frequencies in Example $3(\mathrm{~Hz})$

\begin{tabular}{cccc}
\hline \hline Mode & Chai and Chen $(2009)$ & DQM $(\mathrm{n}=13)$ & DQM $(\mathrm{n}=15)$ \\
\hline 1 & 1.599 & 1.600 & 1.600 \\
2 & 0.358 & 0.357 & 0.358 \\
3 & 0.148 & 0.141 & 0.149 \\
\hline
\end{tabular}

In this example the first four periods of the building are approximated and compared to the study (Chai and Chen 2009) in Table 5.

\section{Conclusions}

In this study the governing equations for the free vibration analysis of coupled shear walls are formulated and solved numerically using DQM. The whole structure is modeled as a sandwich beam in this method. The governing differential equations of the sytems given in the examples are solved using DQM.

It is observed that the DQM provides satisfactory results. When $\mathrm{n}$ is 15 , the error for the first mode is less than $1.32 \%$ when DQM is used. This method is suitable for the first three modes.

DQM converges faster than FD and FM even though less grid points are used. Also the results are better compared to those achieved by using other methods. The main advantages of the Differential Quadrature Method are its inherent conceptual simplicity and the fact that it is easily programmable. Therefore, it can be used at the concept design stage.

\section{References}

Aksoğan, O., Arslan, H.M. and Choo, B.S. (2003), "Forced vibration analysis of stiffened coupled shear walls using continuous connection method", Eng. Struct., 25, 499-506.

Aksogan, O., Bikce, M., Emsen, E. and Arslan, H.M. (2007), "A simplified dynamic analysis of multi bay stiffened coupled shear walls", Adv. Eng. Softw., 38, 552-560.

Basu, A., Nagpal, A.K., Bajaj, R.S. and Guliani, A. (1979), "Dynamic characteristics of coupled shear walls", $J$. Struct. Eng. ASCE, 105, 1637-1651.

Bellman, R.E. and Casti, J. (1971), "Differential quadrature and long term integration", J. Math. Anal. Appl., 34, 235-238.

Bellman, R.E., Kashef, B.G. and Casti, J. (1972), "Differential quadrature: a technique for the rapid solution of nonlinear partial differential equations", J. Comput. Phys., 10, 40-52.

Bert, C.W., Jang, S.K. and Striz, A.G. (1987), "Two new approximate methods for analyzing free vibration of structural components", AIAA J., 26(5), 612-618.

Bert, C.W., Wang, Z. and Striz, A.G. (1993), "Differential quadrature for static and free vibration analysis of anisotropic plates", Int. J. Solids Struct., 30(13), 1737-1744.

Bert, C.W. and Malik, M. (1996a), "Free vibration analysis of tapered rectangular plates by differential quadrature method: a semi- analytical approach", J. Sound Vib., 190(1), 41-63.

Bert, C.W. and Malik, M. (1996b), "Differential quadrature method in computational mechanics: a review", Appl. Mech. Rev., 49(1), 1-28.

Bozdogan, K.B., Ozturk, D. and Nuhoglu, A. (2009), “An approximate method for static and dynamic analyses 
of multi-bay coupled shear walls", Struct. Des. Tall Spec. Build., 18, 1-12.

Chaallal, O. (1992), "Finite element model for seismic RC coupled walls having slender coupling beams", $J$. Struct. Eng. ASCE, 118(10), 2936-2943.

Chaallal, O. and Ghamallal, N. (1996), "Seismic response of flexibly supported coupled shear walls", J. Struct. Eng. ASCE, 122(10), 1187-1197.

Chaallal, O, Gauthier, D. and Malenfant, P. (1996), "Classification methodology for coupled shear walls", $J$. Struct. Eng. ASCE, 122(12), 1453-1458.

Chai, Y.H. and Chen, Y. (2009), "Reexamination of the vibrational period of coupled shear walls by differential transformation”, J. Struct. Eng. ASCE, 135(11), 1330-1339.

Cheung, Y.K., Hutton, S.G. and Kasemset, C. (1977), "Frequency analysis of coupled shear wall assemblies", Earth. Eng. Struct. D., 5(2), 191-201.

Civalek, Ö. (2004a), "Application of differential quadrature (DQ) and harmonic differential quadrature (HDQ) for buckling analysis of thin isotropic plates and elastic columns", Eng. Struct., 26, 171-186.

Civalek, Ö. and Ülker, M. (2004), "Harmonic differential quadrature (HDQ) for axisymmetric bending analysis of thin isotropic circular plates", Int. J. Struct. Eng. Mech., 17(1), 1-14.

Civalek, Ö. (2004b), "Three different type differential quadrature methods (DQM) for linear buckling analysis of uniform elastic columns", J. Yýldýz Technical University, 4(6), 51-58.

Civalek, Ö. (2005), "Geometrically nonlinear dynamic analysis of doubly curved isotropic shells resting on elastic foundation by a combination of HDQ-FD methods", Int. J. Pres. Vess. Pip., 82(6), 470-479.

Coull, A. and Smith, B.S. (1983), Tall buildings 1. Handbook of structural concrete, Ed. F.K. Kong, R.H. Evans, E. Cohen and F. Roll, Pitman Books Limited, London, England.

Eftekhari, S.A. and Jafari, A.A. (2011), "A new mixed finite element-differential quadrature formulation for forced vibration of beams carrying moving loads", J. Appl. Mech., 78(1), 011020-1-16.

Ha, H.H. and Tan, T.M.H. (1999), “An efficient analysis of continuum shear wall models”, Can. J. Civ. Eng., 26, 425-433.

Karami, G. and Malekzadeh, P. (2003), "Application of a new differential quadrature methodology for free vibration analysis of plates", Int. J. Numer. Meth. Eng., 56, 847-867.

Kaya, B. (2010), "Solution of advection-diffusion equation using the differential quadrature method", KSCE $J$. Civ. Eng., 14(1), 69-75.

Kim, H.S. and Lee, D.G. (2003), “Analysis of shear wall with openings using super elements”, Eng. Struct., 25, 981-991.

Kuang, J.S. and Chau, C.K. (1998), "Free vibration of stiffened coupled shear walls", Struct. Des. Tall Build., 7, $135-145$.

Kwan, A.K.H. (1993), "Mixed finite elements for analysis of coupled shear/core walls", J. Struct. Eng. ASCE, 119(59), 1388-1408.

Kwan, A.K.H. (1995), "Equivalence of finite elements and analogous frame modules for shear/core wall analysis", Comp. Struct., 57(2), 193-203.

Li, G.Q. and Choo, B.S. (1996), "A continous-discrete approach to the free vibration analysis of stiffened pierced walls on flexible foundations", Int. J. Solids Struct., 33(2), 249-263.

Liew, K.M., Teo, T.M. and Han, J.B. (1999), "Comparative accuracy of DQ and HDQ methods for threedimensional vibration analysis of rectangular plates", Int. J. Num. Meth. Eng., 45, 1831-1848.

Liew, K.M. and Teo, T.M. (1999), "Three dimensional vibration analysis of rectangular plates based on differential quadrature method", J. Sound Vib., 220(4), 577-599.

Liew, K.M., Teo, T.M. and Han, J.B. (2001), "Three dimensional static solutions of rectangular plates by variant differential quadrature method", Int. J. Mech. Sci., 43, 1611-1628.

Malekzadeh, P. and Farid, M. (2007), "A DQ large deformation analysis of composite plates on nonlinear elastic foundations", Compos. Struct., 79, 251-260.

Potzta, G. and Kollar, L.P. (2003), "Analysis of building structures by replacement sandwich beams", Int. J. Solids Struct., 40, 535-553.

Rashed, Y.F. (2000), "Analysis of building shear walls using boundary elements", Eng. An. Bound. Elem., 24, 287-293.

Resatoglu, R., Aksogan, O. and Emsen, E. (2010), "Static analysis of laterally arbitrarily loaded non-planar non 
symmetrical coupled shear walls", Thin Wall. Struct., 48(9), 696-708.

Rosman, R. (1964), "Approximate analysis of shear walls subject to lateral loads", Proc. Am. Concr. Inst., 61(6), 717-734.

Smith, B.S. (1970), "Modified beam method for analyzing symmetrical shear walls". J. Am. Concr. Inst., 67(2), 977-980.

Shu, C. and Richards, B.E. (1992), "Application of generalized differential quadrature to solve two-dimensional incompressible navier-stokes equations", Int. J. Num. Meth. Fluids, 15, 791-798.

Shu, C. and Xue, H. (1997), "Explicit computations of weighting coefficients in the harmonic differential quadrature", J. Sound Vib., 204(3), 549-555.

Shu, C. (2000), Differential quadrature and its application in engineering, Springer-Verlag London Limited.

Striz, A.G., Jang, S.K. and Bert, C.W. (1988), "Nonlinear bending analysis of thin circular plates by differential quadrature", Thin Wall. Struct., 6, 51-62.

Striz, A.G., Wang, X. and Bert, C.W. (1995), "Harmonic differential quadrature method and applications to analysis of structural components", Acta Mech., 111, 85-94.

Takabatake, H. (2010), "Two- dimensional rod theory for approximate analysis of building structures", Earthq. Struct., 1(1), 1-19.

Wang, Q. and Wang, L.Y. (2005), "Estimating periods of vibration of buildings with coupled shear wall", $J$. Struct. Eng. ASCE, 131(12), 1931-1935.

Zeidabadi, N.A., Mirtalae, K. and Mobasher, B. (2004), "Optimized use of the outrigger system to stiffen the coupled shear walls in tall buildings", Struct. Des. Tall Spec. Build., 13, 9-27. 